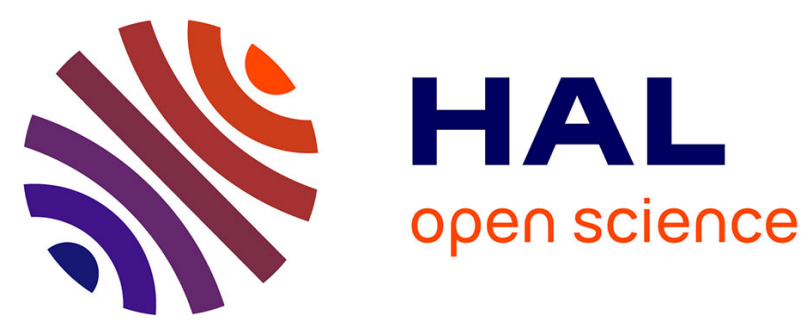

\title{
Plasma hydrogenated cationic detonation nanodiamonds efficiently deliver to human cells in culture functional siRNA targeting the Ewing sarcoma junction oncogene
} Jean-Rémi Bertrand, Catherine Pioche-Durieu, Juan A. Ayala, Tristan Petit, Hugues Girard, Claude Malvy, Eric Le Cam, François Treussart, Jean-Charles Arnault

\section{To cite this version:}

Jean-Rémi Bertrand, Catherine Pioche-Durieu, Juan A. Ayala, Tristan Petit, Hugues Girard, et al.. Plasma hydrogenated cationic detonation nanodiamonds efficiently deliver to human cells in culture functional siRNA targeting the Ewing sarcoma junction oncogene. Biomaterials, 2015, 45, pp.93 - 98. 10.1016/j.biomaterials.2014.12.007 . cea-01807460

\section{HAL Id: cea-01807460 https://hal-cea.archives-ouvertes.fr/cea-01807460}

Submitted on 7 Jun 2021

HAL is a multi-disciplinary open access archive for the deposit and dissemination of scientific research documents, whether they are published or not. The documents may come from teaching and research institutions in France or abroad, or from public or private research centers.
L'archive ouverte pluridisciplinaire HAL, est destinée au dépôt et à la diffusion de documents scientifiques de niveau recherche, publiés ou non, émanant des établissements d'enseignement et de recherche français ou étrangers, des laboratoires publics ou privés. 


\title{
Plasma hydrogenated cationic detonation nanodiamonds efficiently deliver to human cells in culture functional siRNA targeting the Ewing sarcoma junction oncogene
}

\author{
J.-R. Bertrand, ${ }^{a}$ C. Pioche-Durieu, ${ }^{b}$ J. Ayala, ${ }^{a}$ T. Petit, ${ }^{c}$ H. A. Girard,${ }^{c}$ C. P. Malvy ${ }^{a}$, E. Le Cam, ${ }^{b}$ \\ F. Treussart, ${ }^{d}$ and J.-C. Arnault ${ }^{c}$ \\ a Laboratoire de Vectorologie et Thérapeutiques Anticancéreuses, UMR 8203 CNRS, \\ Université Paris Sud, Institut Gustave Roussy, 94805 Villejuif, France. E-Mail: jean- \\ remi.bertrand@gustaveroussy.fr \\ ${ }^{b}$ Signalisation, Noyaux et Innovations en Cancérologie, UMR 8126 CNRS, Université Paris \\ Sud, Institut Gustave Roussy, 94805 Villejuif, France \\ c CEA, LIST, Diamond Sensors Laboratory, F-91191 Gif-sur-Yvette, France. E-Mail: jean- \\ charles.arnault@cea.fr \\ ${ }^{d}$ Laboratoire Aimé Cotton, CNRS, Université Paris Sud and ENS Cachan, 91405 Orsay, France. \\ E-Mail : francois.treussart@ens-cachan.fr
}

\begin{abstract}
The expression of a defective gene can lead to major cell dysfunctions among which cell proliferation and tumor formation. One promising therapeutic strategy consists in silencing the defective gene using small interfering RNA (siRNA). In previous publications we showed that diamond nanocrystals (ND) of primary size $35 \mathrm{~nm}$, rendered cationic by polyethyleneimine-coating, can efficiently deliver siRNA into cell, which further block the expression of EWS/FLI-1 oncogene in a Ewing sarcoma disease model. However, a therapeutic application of such nanodiamonds requires their elimination by the organism, particularly in urine, which is impossible for $35 \mathrm{~nm}$ particles. Here, we report that hydrogenated cationic nano- diamonds of primary size $7 \mathrm{~nm}(\mathrm{ND}-\mathrm{H})$ have also a high affinity for siRNA and are capable of delivering them in cells. With siRNA/ND-H complexes, we measured a high inhibition efficacy of EWS/FLI-1 gene expression in Ewing sarcoma cell line. Electron microscopy investigations showed ND-H in endocytosis compartments, and especially in macropinosomes from which they can escape before siRNA degradation occurred. In addition, the association of EWS/FLI-1 silencing by the siRNA/ND-H complex with a vincristine treatment yielded a potentiation of the toxic effect of this chemotherapeutic drug. Therefore ND-H appears as a promising delivery agent in antitumoral gene therapy.
\end{abstract}

\section{Introduction}

In recent years, nanodiamonds (NDs) have gained increasing attention as powerful nanoplatform with fluorescent labeling ca- pacities for both diagnostic and therapeutic purposes $[1,2]$. Indeed, NDs have properties that make them highly suitable for biomedical applications: several in vitro [3] and in vivo [4] studies have shown that NDs are noncytotoxic with an enhanced cell tolerance compared to other carbon nanoparticles, and their carbon-related surface chemistry is interesting for covalent or non-covalent functionalization 
of therapeutic, targeting or labeling moieties (drugs, oligonucleotides, proteins, fluorescent dyes) $[5,6]$. In this context, small interfering RNA (siRNA) is a powerful agent for gene inhibition, but its activity is limited by a poor capacity to penetrate into cells and by the degradation by nucleases. For this reason, several groups have developed vectors to deliver efficiently oligo- nucleotides [7] and siRNA to cells [8]. In previous studies we showed that synthetic NDs of primary core size around $35 \mathrm{~nm}$, produced by high-pressure and high temperature synthesis (HPHT), can deliver active siRNA to cells in culture resulting in inhibiting the expression of Ewing sarcoma junction oncogene EWS/FLI-1 in Ewing human cells $[9,10]$. These NDs were carboxyl- ated by strong acid cleaning resulting in a negative surface charge at $\mathrm{pH}$ 7. They were then coated with cationic polymers (poly- ethylene-imine [PEI] or polyallylamine hydrochloride [PAH]) so that negatively charged siRNA can bind to them by electrostatic interaction. This strategy has revealed to be efficient with a low toxicity for the transfected cell and a good gene inhibition. How- ever, it cannot be translated to animals because of the vector size (further increased to about $120-130 \mathrm{~nm}$ after polymer coating [9]) preventing its elimination in urine after intravenous injection [11]. Moreover, since the polymer is non-covalently bound to the ND vector, it may dissociate from its surface after injection to the animals, taking the siRNA away with it, which results in a loss of the expected gene inhibition.

In this study, we used intrinsically cationic nanodiamonds [12] of $7 \mathrm{~nm}$ primary core size, which could be compatible with in vivo applications. Indeed, one can expect their elimination by kidney [11]. These nanodiamonds produced by detonation of high energy explosives (hexogen/RDX) [13] were exposed to a micro- wave hydrogen plasma leading to an efficient cleaning of oxygen groups, a removal of non-diamond carbon and the formation of $\mathrm{C} \mathrm{sp} \mathrm{sp}^{3} \mathrm{H}$ terminations as previously reported [12,14,15]. After plasma exposure, hydrogenated detonation ND (ND-H) were dispersed in water forming a stable suspension with a positive zeta potential of $50 \mathrm{mV}$ favorable to nucleic acids electrostatic binding. The origin of the positive Zeta potential was recently explained by a surface transfer doping mechanism [16]. In this work, we show that siRNA binds to ND-H, and we demonstrate that the siRNA/ND-H complex can efficiently deliver siRNA promoting EWS/FLI-1 targeted gene silencing into human Ewing sarcoma cells in culture. These results establish a first step towards applications to small animals of ND vector that could be eliminated in urine owing to its ultrasmall size.

\section{Experimental section}

\subsection{Cationic ND-H and anionic ND-COOH preparation and characterization}

Detonation nanodiamonds were provided by the NanoCarbon Institute Co., Ltd. (Japan). Hydrogenation of nanodiamonds was achieved by microwave-enhanced plasma treatments. A mass of $80 \mathrm{e} 100 \mathrm{mg}$ of NDs was deposited in a quartz tube and inserted in a plasma Downstream source (Sairem SAS, France). High purity hydrogen gas (>N70) was injected in the tube at a pressure of $15 \mathrm{mbar}$ and plasma was generated in the quartz tube at a micro- 
wave power of $300 \mathrm{~W}(2.45 \mathrm{GHz})$. During the plasma, the tube was air-cooled. NDs were exposed to hydrogen plasma for $15 \mathrm{~min}$ and were cooled down under hydrogen, leading to ND-H. More details were previously reported [12]. ND-H were then dispersed in ultrapure water by sonication (UP400S, 300 W, 24 kHz, Hielscher Ultrasonics GmbH, Germany) for $2 \mathrm{~h}$ under cooling. Larger aggregates were removed from the solution by centrifugation at 4000 $\mathrm{rpm}$ (30 min or $2 \mathrm{~h}$ depending on the sample). Oxidized NDs (ND-COOH) were obtained by air annealing $\left(400^{\circ} \mathrm{C}\right.$ for $\left.2 \mathrm{~h}\right)$ and dispersed in ultrapure water by the same sonication procedure than ND-H. Size and Zeta potential measurements of ND-H and ND-COOH suspensions were performed in ultrapure water on a Nanosizer ZS (Malvern, UK) in the back scattering configuration $\left(173^{\circ}\right)$.

\section{2. siRNA binding to ND-H}

The binding capacity of cationic hydrogenated ND-H was studied by mixing $28 \mathrm{ng}$ of siRNA in $30 \mu \mathrm{L}$ of $10 \mathrm{mM}$ HEPES buffer at $\mathrm{pH}=7.2$ and $100 \mathrm{mM} \mathrm{NaCl}$, with increasing concentration of $\mathrm{ND}-\mathrm{H}$ ranging from 0 to $0.1 \mu \mathrm{g} / \mu \mathrm{L}$. After $10 \mathrm{~min}$ incubation at room temperature, the solution was centrifuged at speed $13000 \mathrm{rpm}$, for $10 \mathrm{~min}$ and at $15^{\circ} \mathrm{C}$. Then $30 \mu \mathrm{L}$ of supernatant was mixed with $30 \mu \mathrm{L}$ of $1 \mu \mathrm{g} / \mathrm{mL}$ ethidium bromide (Sigma-Aldric, USA) and fluorescence was recorded with a fluorescence plate reader with excitation wavelength of $525 \mathrm{~nm}$, and detection range 580-640 nm (GloMax ${ }^{\circledR}$-Multi, Promega). Experiments were performed in triplicate. siRNA labeled with FITC dye (siRNA-FITC) was used to identify the location of siRNA in cell by epifluorescence microscopy.

\subsection{Cytotoxicity}

A673 human Ewing sarcoma cell line was a generous gift from Dr. Elizabeth R. Lawlor (University of Michigan, USA). Cells were grown in DMEM medium supplemented by $10 \%$ of fetal bovine serum (Gibco) and $1 \%$ penicillin-streptomycin antibiotics (Gibco). One day before treatment, $2 \times 10^{3}$ cells by well were plated in 96 wells and incubated at $37^{\circ} \mathrm{C}, 5 \% \mathrm{CO}_{2}$ in moistly atmosphere. The medium was then removed and replaced by $100 \mu \mathrm{L}$ medium containing increasing concentrations of either ND-H or ND-COOH from 0 to $0.3 \mathrm{mg} / \mathrm{mL}$. Two series were treated with ND mixed with $50 \mathrm{nM}$ siRNA. Cells were incubated for $48 \mathrm{~h}$ and the cell viability was then determined using a MTT assay. Briefly, $10 \mu \mathrm{L}$ of $5 \mathrm{mg} / \mathrm{mL}$ MTT in PBS buffer were added and cells were incubated for $2 \mathrm{~h}$. Then, $100 \mu \mathrm{L}$ of lysis buffer $(10 \mathrm{mH} \mathrm{HCl}$, $10 \%$ SDS) was added overnight and the produced formazan was quantified on cell suspension by absorbance measurement at $570 \mathrm{~nm}$ wavelength using a micro plate reader (EL 808, BioTek, USA). Experiments were performed in 8 replicates. Data were corrected from the absorbance/scattering of free ND suspension. For such correction, a 96 wells plate is seeded with just ND solution in increasing concentration and MTT treatment is performed as for cell cytotoxicity test. Then optical density is measured with the microplate reader and the value corresponding to each ND concentration is subtracted to the one measured for cells treated with the same ND concentration. Results are expressed as $\%$ of untreated cells.

\section{4. siRNA delivery to cells: epifluorescence microscopy observations.}


A673 cells $\left(2 \times 10^{5}\right.$ cells per well) were seeded $24 \mathrm{~h}$ before the addition of cationic ND in 12 wells plate with $18 \mathrm{~mm}$ diameter coverslips at the bottom, and containing $500 \mu \mathrm{l}$ DMEM medium (Gibco) with $10 \%$ bovine calf serum (Gibco) and 1\% Penicillin/streptomycin solution (Gibco). The culture was done at $37{ }^{\circ} \mathrm{C}, 5 \% \mathrm{CO}_{2}$ in moistly atmosphere. The medium was then discarded and replaced by $500 \mu \mathrm{L}$ of the same medium or serum free Opti-MEM medium (Gibco) containing ND-H/siRNA-FITC fluorescent conjugate at mass ratio of 10, 25, 50 and 75 (ND/siRNA, $\mu \mathrm{g} / \mu \mathrm{g}$ ), at final siRNA concentration of $50 \mathrm{nM}$. The mass-ratio corresponds to the mixed masses of NDs and siRNA. The ND-H/siRNA-FITC were incubated with cells for 4 hours at $37{ }^{\circ} \mathrm{C}, 5 \% \mathrm{CO}_{2}$ in moistly atmosphere. Then, the cells were washed twice with $1 \mathrm{~mL}$ PBS and fixed with $4 \%$ formaldehyde in PBS for $20 \mathrm{~min}$ at room temperature. The cells were washed with PBS and mounted on microscope slide with Dapi Fluoromount G (Southern Biotech, USA). The internalization of ND-H/siRNA-FITC by the cells was monitored with an epifluorescence microscope (Observer, Zeiss, Germany).

\section{5. siRNA delivery to cells: confocal microscopy and fluorescence spectroscopy.}

Confocal raster scans (Supporting Information Fig. S2) were done with a home-made microscope described in Ref. [17], equipped with single photon counting module capable of detecting single nitrogen color center. Neutraly charged nitrogen-vacancy color center emission having a maximum around $615 \mathrm{~nm}$ wavelength, was detected in the microscope red channel. The confocal microscope excitation source is a continuous wave (cw) solid-state laser (561L-100-COL-PP, Oxxius SA, France) emitting at the wavelength $561 \mathrm{~nm}$. The red detection channel consists in a longpass detection/emission filter with a steep edge at $580 \mathrm{~nm}$ and an optical density larger than 6 at $561 \mathrm{~nm}$ (BLP01-561R-25, Semrock, USA). The microscope green detection channel allowing to detect FITC dye fluorescence is composed of a cw solid-state laser emitting at $488 \mathrm{~nm}$ wavelength (Sapphhire 488-50, Coherent Inc., USA), and a detection/emission bandpass filter centered on $525 \mathrm{~nm}$ (ET525/50, Chroma Corp., USA). Both $561 \mathrm{~nm}$ and $488 \mathrm{~nm}$ beam were focused onto the sample via an immersion oil x60, numerical aperture 1.40 microscope objective (CFI Plan Apochromat DM60x oil, Nikon, Japan) after their combination and reflection onto a double-band dichroic filter (Di01R488/561, Semrock). The fluorescence spectrum displayed on Fig. S1f was acquired with an imaging spectrograph (MicroHR MHRA-1X-AMS equipped with Symphony CCD-1024x256BIUV-STE Open electrode cooled CCD array detector, Horiba Jobin Yvon, France).

\section{6. siRNA delivery to cells: TEM studies.}

For TEM studies, the cells were seeded in 12 wells plates containing a coverslip at $8 \times 10^{4}$ cells per wells $24 \mathrm{~h}$ before the addition of ND. Then the medium was discarded and replaced by $500 \mu \mathrm{L}$ of DMEM medium containing $10 \%$ bovine calf serum or free serum OptiMEM medium containing $40 \mu \mathrm{g} / \mathrm{mL}$ of NDs- $\mathrm{H}$. The cells were incubated for $3 \mathrm{~h}$ at $37^{\circ} \mathrm{C}, 5 \% \mathrm{CO}_{2}$ in a moistly atmosphere. The medium was discarded and replaced by $1 \mathrm{~mL}$ of $2 \%$ glutaraldehyde (EMS, Hatfield, PA, USA) in $0.1 \mathrm{M}$ cacodylate buffer $\mathrm{pH}=7.4$, for $1 \mathrm{~h}$ at room temperature. Cells were post-fixed for 1 hour at room temperature with $1 \%$ osmium tetroxide and $1.5 \%$ potassium ferrocyanide (Sigma-Aldrich,France) (EMS,Hatfield, PA, USA) in 
cacodylate buffer. They were dehydrated by increasing concentrations of ethanol and finally embedded in Epon812 epoxy resin (EMS, Hatfield, PA, USA). The polymerization was carried out by heating the sample during 72 hours at $56^{\circ} \mathrm{C}$. It was then sectioned with a microtome (thickness $90 \mathrm{~nm}$ ), and the sections were collected on collodion-carbon-coated copper grids. Sections were contrasted using aqueous uranyl acetate 2\% (w/v) (Merck, France) and lead citrate solutions (Reynold's stain). The samples were observed with Zeiss 902 TEM in the filtered zero loss modes using a CCD array detector (Megaview III, Olympus, Japan) coupled to the SIS software (Olympus).

\subsection{Inhibition of EWS/FLI-1 gene expression}

$24 \mathrm{~h}$ before treatment, $5 \times 10^{4} \mathrm{~A} 673$ cells are seeded per wells in 12 wells plate with 500 $\mu \mathrm{L}$ DMEM medium (Gibco) containing $10 \%$ bovine calf serum and $1 \%$ penicillin/streptomycin (Gibco) and incubated at $37^{\circ} \mathrm{C}, 5 \% \mathrm{CO}_{2}$ in moistly atmosphere. Then, medium was removed and replaced by $450 \mu \mathrm{L}$ of same medium and $50 \mu \mathrm{L}$ of $10 \mathrm{mM}$ Hepes $\mathrm{pH} 7.2,100 \mathrm{mM} \mathrm{NaCl}$ containing free siRNA or NDs-H bounded siRNA targeted toward EWS/FLI-1 or control sequence to $50 \mathrm{nM}$ final concentration. siRNA/ND mass ratio is $50(\mathrm{w} / \mathrm{w})$. Cells were incubated for 24 hours and total RNA was extracted by Trizol (Invitrogen, USA) methods. Briefly, the cell culture medium is discarded first. Cells are then washed with PBS and lysed with $800 \mu \mathrm{L}$ of Trizol solution. Finally, the cells are scrapped and $160 \mu \mathrm{L}$ of chloroform/isoamyl alcohol (49/1) are added. The solution is centrifuged at $13000 \mathrm{rpm}$ for $15 \mathrm{~min}$ at $4^{\circ} \mathrm{C}$. $300 \mu \mathrm{L}$ of the supernatant containing the RNA were added to the same volume of isopropanol and RNA precipitation was obtained after $15 \mathrm{~min}$ at room temperature. The solutions are then centrifuged $13000 \mathrm{rpm}$ for $15 \mathrm{~min}$ at $4^{\circ} \mathrm{C}$ and the pellet is washed twice with $70 \%$ ethanol and dried. The total extracted RNA was dissolved in $10 \mu \mathrm{L}$ of water containing $0.5 \mathrm{U}$ RNasin (Promega, USA) and the RNA concentration was determined by spectrophotometry at $260 \mathrm{~nm}$ (Nanodrop, ThermoFisher, USA ). The reverse transcription was performed on $1.5 \mu \mathrm{g}$ of total RNA by adding $2 \mu \mathrm{l}$ of random hexamers at a concentration of $50 \mu \mathrm{g} / \mathrm{mL}$ (Promega), and heating at $65^{\circ} \mathrm{C}$ for $5 \mathrm{~min}$. The RNA was then incubated with $0.5 \mu \mathrm{L}$ M-MLV reverse transcriptase $200 \mathrm{U} / \mu \mathrm{L}, 0.5 \mu \mathrm{L} 20 \mathrm{mM}$ DNTP, $0.5 \mu \mathrm{L}$ RNasin $(40 \mathrm{U} / \mu \mathrm{L})$ and $4 \mu \mathrm{L}$ of $5 \mathrm{x}$ buffer (Promega) for $1 \mathrm{~h}$ at $42^{\circ} \mathrm{C}$. PCR quantification was carried out with qPCR SuperMix SYBR GreenER (Invitrogen, France). The EWS/FLI-1 gene was amplified with the EWS- Forward Primer: 5'-AGC AGT TAC TCT CAG CAG AAC ACC-3' and FLI1-reverse primer: 5'-CCA GGA TCT GAT ACG GAT CTG GCT G-3' (Eurogentec, Belgium). We mixed $1 \mu \mathrm{L}$ of each primer, at a concentration of $10 \mu \mathrm{M}$, with $5 \mu \mathrm{L}$ of cDNA diluted $1 / 20(\mathrm{v} / \mathrm{v})$ in a final volume of $25 \mu \mathrm{L}$. The samples were amplified over 45 cycles, in a 7900 Fast RealTime PCR System (Applied Biosystems, USA), as follows: 2 minutes of incubation at $50^{\circ} \mathrm{C}, 10$ min at $95^{\circ} \mathrm{C}$, followed by 45 cycles of $95^{\circ} \mathrm{C}$ for 15 seconds, $60^{\circ} \mathrm{C}$ for $1 \mathrm{~min}$. The human $18 \mathrm{~S}$ rRNA gene was used as a control and was amplified with the $18 \mathrm{~S}$ Forward Primer $5^{\prime}$-CGT TCA GCC ACC CGA GAT-3', and 18S reverse primer 5' TAA TGA TCC TTC CGC AGG TT-3'. The Ct obtained was between 10 and 16 for $18 S$ and between 20 and 24 for EWS/FLI-1. Comparative $\mathrm{Ct}$ methods were used to normalize the target $\mathrm{Ct}$ by the $18 \mathrm{~S}$ control gene $\mathrm{Ct}$. 


\subsection{Effect of the association of ND-H vectorized siRNA and Vincristine on cell growth}

One day before treatment, $2 \times 10^{3}$ A673 cells in $100 \mu \mathrm{L}$ were seeded per wells in 96 wells plate in DMEM medium (Gibco) containing $10 \%$ bovine calf serum and $1 \%$ penicillin/streptomycin (Gibco) and incubated at $37^{\circ} \mathrm{C}, 5 \% \mathrm{CO}_{2}$ in moistly atmosphere. Then, the medium was removed and replaced by $100 \mu \mathrm{L}$ of the same medium containing $0.3 \mathrm{ng} / \mathrm{mL}$ of vincristin and ND-H vectorized siRNA antisens or control at $50 \mathrm{nM}$ siRNA and ND-H at molar ratio of 50 (siRNA/ND-H, W/W). The cells were incubated for 48 hours and their viability was determined by a MTT assay as described above. The results are expressed as \% of untreated cells. Statistical tests were performed with Instat software (Graphpad software Inc, USA) using the Friedman Test (Nonparametric Repeated Measures ANOVA).

\section{Results and discussion}

\subsection{Binding of SiRNA on ND-H}

Hydrogenated detonation nanodiamonds (ND-H) exhibit a primary core size of $\sim 7 \mathrm{~nm}$ [12]. After their dispersion in water and a short centrifugation of $30 \mathrm{~min}$, dynamic light scattering (DLS) measurements report a hydrodynamic diameter of $\sim 30 \mathrm{~nm}$ and $E_{\text {ZETA }}=+55 \mathrm{mV}$ (see Supporting Information Fig. S1a). A longer centrifugation duration ( 2 hours) lead to a suspension constituted of isolated particles, with a hydrodynamic diameter reduced to $7 \mathrm{~nm}$ as shown on Fig. S1c. However, the concentration was drastically reduced in that case. In this study, size $\approx 30 \mathrm{~nm}$ aggregates of $7 \mathrm{~nm}$ ND-H were thus used for the proof of concept. Starting with this material, the capacity of ND-H to bind siRNA by electrostatic interaction was measured after incubation of an increasing concentration of ND-H at a fixed quantity of siRNA. After centrifugation, free siRNA in the supernatant was quantified thanks to ethydium bromide coloration (Fig. 1). 


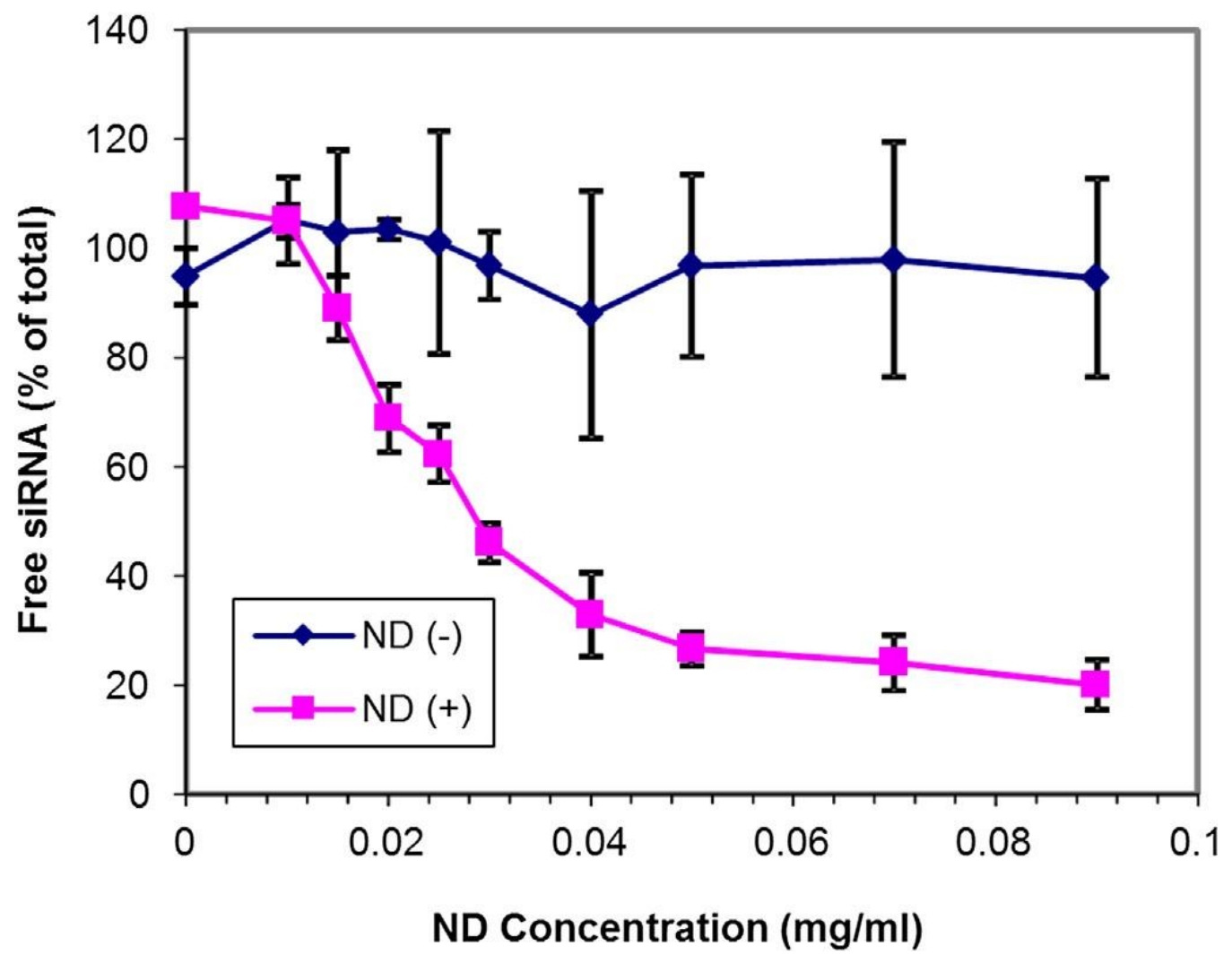

Fig. 1. siRNA binding to cationic ND-H (square) or to anionic ND-COOH (diamond). Free siRNAs are detected in the supernatant after centrifugation of the samples. Experiment performed in triplicate. In the case of ND-H (+) the remaining $20 \%$ free siRNA may be due to the oligonucleotide detachment during the ultracentrifugation separation step.

When the ND-H concentration was increased, the free siRNA decreased due to the binding on ND-H. The minimum ND-H concentration capable to bind $80 \%$ of siRNA is $40 \mu \mathrm{g} / \mathrm{mL}$ for a siRNA concentration of $0.8 \mu \mathrm{g} / \mathrm{mL}$ corresponding to a mass ratio of 50 (ND/siRNA, w/w). As a comparison, using the same detonation NDs (size $=7 \mathrm{~nm}$ ) that were carboxylated instead of hydrogenated in order to provide them a negative charge $\left(E_{\text {ZETA }}=-\right.$ $50 \mathrm{mV}$, see Fig. S1b), we did not observe siRNA/nanodiamond binding as expected from electrostatic repulsion.

The observed binding capacity corresponds to $16 \mathrm{mg}$ of siRNA (corresponding to $1.23 \mu$ moles) for $1 \mathrm{~g}$ of ND-H. Surprisingly, it is similar to the one of polymeric-coated HPHT ND exhibiting an overall diameter of $120 \mathrm{~nm}$, for which $14 \mathrm{mg}$ of siRNA can be bound to $1 \mathrm{~g}$ of ND/Polyallylamine chloride [9]. To determine the optimal conditions cell delivery efficacy two parameters needed to be studied: i) the toxicity of NDs and ii) the mass ratio between siRNA and NDs.

\subsection{Cytotoxicity assay}

The toxicity of detonation anionic ND-COOH and cationic ND-H was determined after 48 hours treatment of $\mathrm{A} 673$ human Ewing sarcoma cell by a MTT proliferation test. Cationic and anionic NDs were used with or without $50 \mathrm{nM}$ siRNA (corresponding to a siRNA concentration of $0.65 \mu \mathrm{g} / \mathrm{mL}$ ) covering their surface. A toxicity (death of more than $50 \%$ of the cells) was observed at ND concentrations larger than $50 \mu \mathrm{g} / \mathrm{mL}$ (Fig. 2). Cationic NDs are 
more toxic than anionic, with an $\mathrm{IC}_{50}$ of $0.05 \mathrm{mg} / \mathrm{mL}$ for $\mathrm{ND}-\mathrm{H}$, to be compared to $0.15 \mathrm{mg} / \mathrm{mL}$ for ND-COOH.

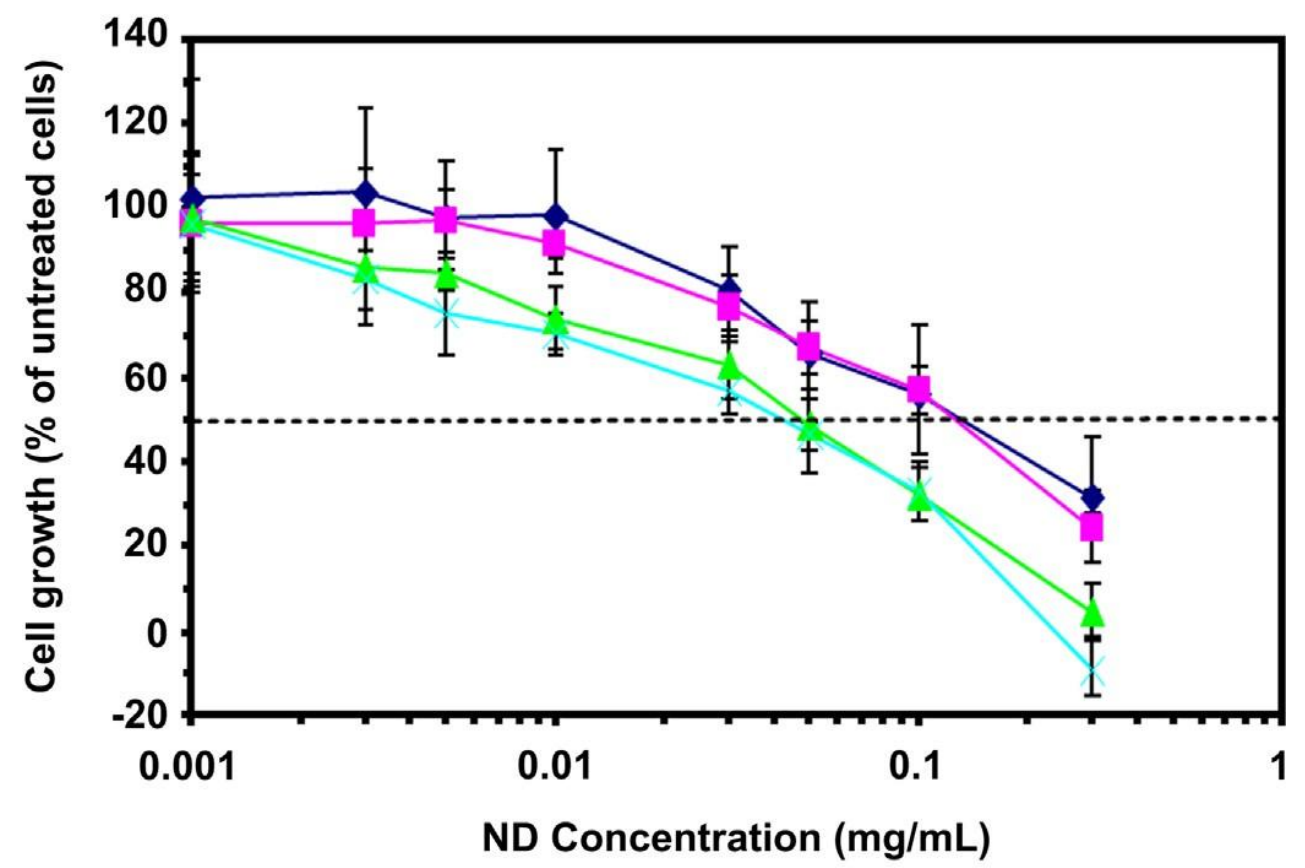

$\neg$ ND5- - - ND5- siRNA $\leftarrow$ ND5+ $\longleftarrow$ ND5+ siRNA

Fig. 2. Cytotoxicity of anionic and cationic NDs. Human Ewing cells $A 673$ were treated for $48 \mathrm{~h}$ with an increasing concentration of ND-H or ND-COOH in presence or in absence of siRNA, in a mass ratio of 50. The results are expressed in percentage of untreated cells and corrected from de ND absorption at $570 \mathrm{~nm}$.

The presence of siRNAs does not modify this effect. Because diamond solutions absorb light at the wavelength of $570 \mathrm{~nm}$ used to determine the survival curves by spectroscopic measurement (in the MTT assay), these curves were corrected from this absorption. The higher toxicity of cationic ND compare to the anionic one may be due to the interaction of positively charged particles with the cell membranes as generally observed for cationic vectors.

\subsection{Internalization efficiency and Subcellular localization of detonation ND-H in cells studied} by transmission electron microscopy (TEM)

To evaluate the internalization efficiency of the cationic ND-H, we used fluorescent siRNA and observed their cell penetration into A673 human Ewing sarcoma cells. The cells were incubated for $3 \mathrm{~h}$ with FITC labeled siRNA free or bound to an increasing amount of ND-H from 0 to 75 ND-H/siRNA mass ratio. We observed on Fig. 3 that free siRNA are not detected in cell confirming the absence of spontaneous penetration. Green FITC-siRNA fluorescence is detectable for ND-H/siRNA mass ratio larger than 10 . These results were confirmed by fluorescence confocal microscopy (see Fig. S2) showing NDs detected thanks to their redemitting fluorescence due to the presence of embedded nitrogen vacancy color centers [18]. Note that the cell morphology is slightly modified for siRNA/ND-H mass ratio of 75 suggesting some toxic effect due to large amount of aggregates into cells. 

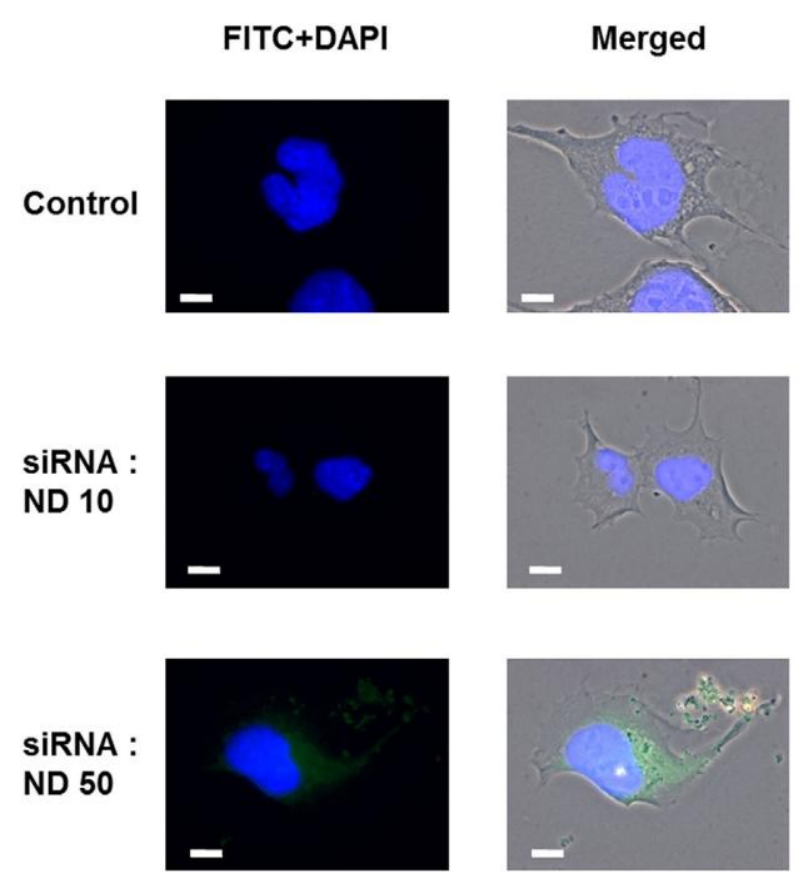

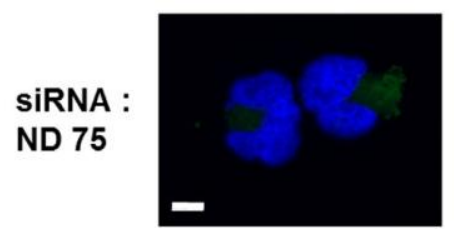

Merged

SIRNA
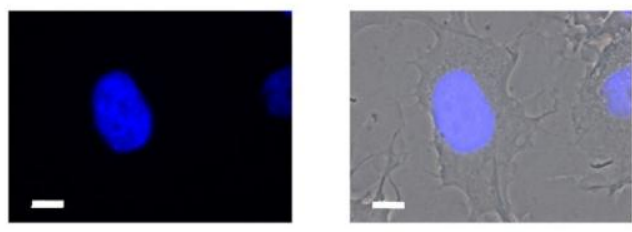

SIRNA : ND 25
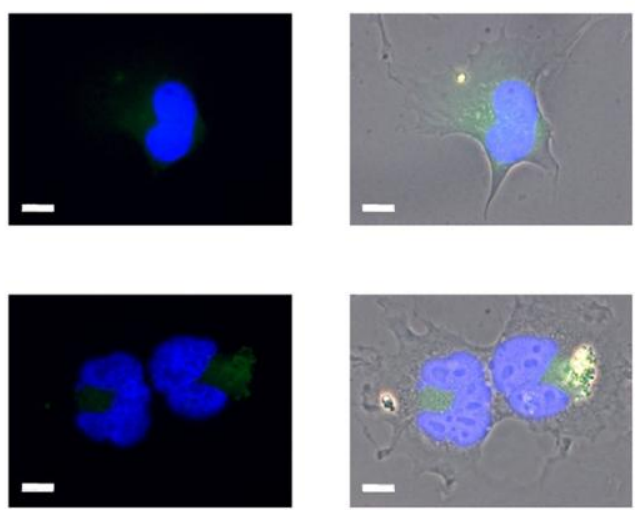

Fig. 3. Internalization of ND-H/siRNA complexes in A673 cells after 3 h. 50 nM FITC labeled siRNA was used with an increasing quantity of ND-H at different mass ratio (from 10 to 75; ND-H/siRNA). The cells were observed by epifluorescence microscopy after nucleus coloration with DAPI. Left panels display DAPI and FITC fluorescence signals, and the right panels correspond to white light illumination phase contrast images (transmission) merged with the fluorescence ones. Scale bar: $10 \mu \mathrm{m}$.

To detect the localization of ND-H within the cell ultrastructure, we carried out TEM experiments observation in a similar way than in our previous studies [10] with larger ND from HPHT synthesis. Two types of cell preparation were used. In the first one, the pellet obtained by centrifugation of trypsinated cells was embedded in resin before sectioning. With this conventional method, the cell plasmic membrane is clearly visible. Indeed, due to the spherical shape of the trypsinated cells, the membrane is perpendicular to the section orientation (Fig. 4a). In the second method, cells grown as a flat monolayer on the glass coverslip are embedded in the resin before sectioning. This method keeps the morphological aspect of the cells but their membrane may not be as well defined as in the pellet embedding approach (Fig. 4c). We observed that ND-H enter by the same two mechanisms already identified for 50-100 nm ND/PAH: [10] clathrin mediated endocytosis as evidenced by clathrin pits (inset of Fig. 4a), endosomes (Fig. 4a) and lysosomes (Fig. 4b); and macropinocytosis since large macropinosomes can be seen (Fig. 4c). 

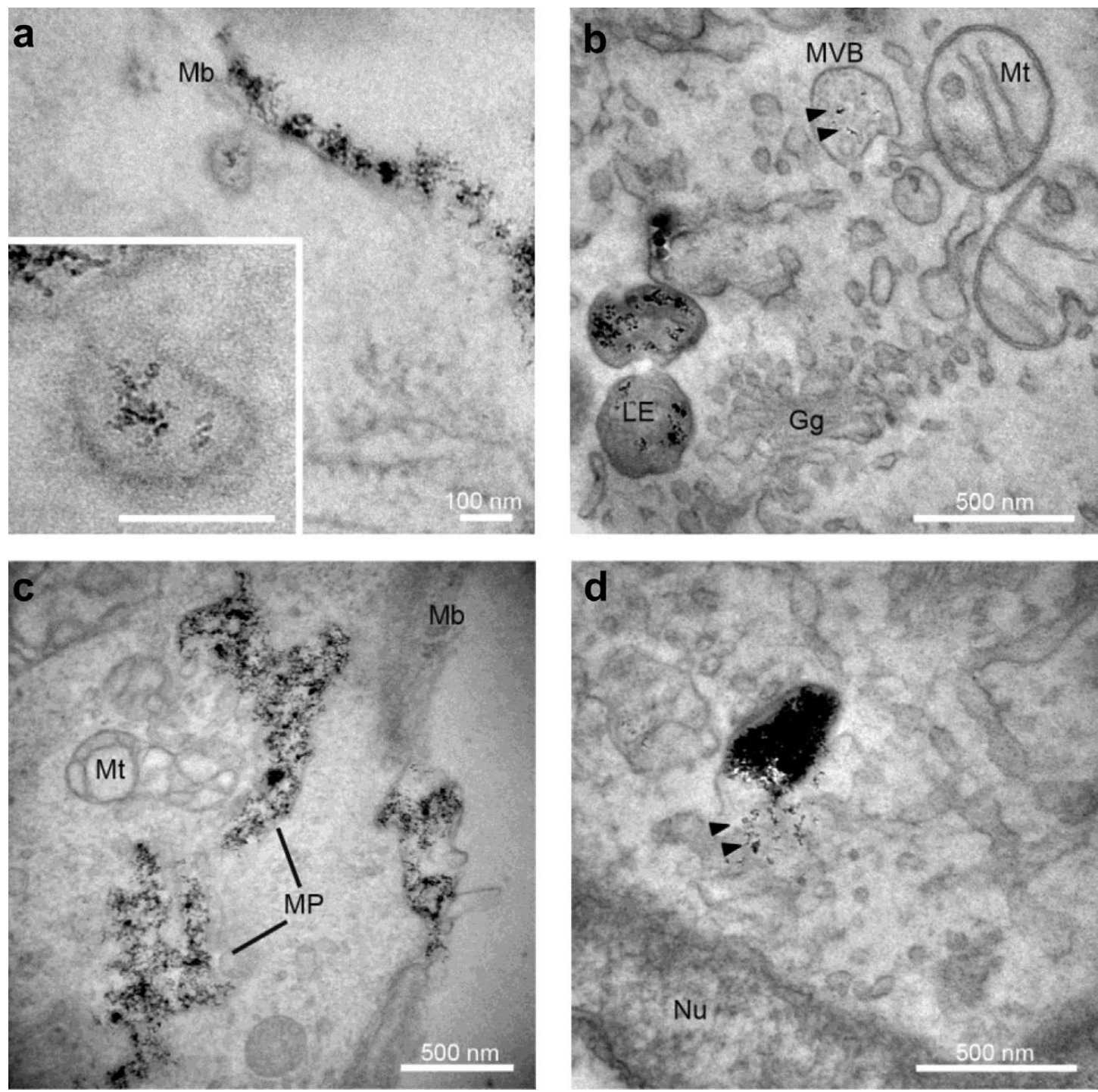

Fig. 4. TEM images of $A 673$ cells incubated with $7 \mathrm{~nm} N D-H$ for $3 \mathrm{~h}$, and sectioned at $90 \mathrm{~nm}$ thickness after epoxy resin embedding. Sections staining was done with uranyl acetate and lead citrate. (a) ND-H are observed at the cell membrane. They penetrate by clathrin-mediated endocytosis (inset: clathrin pit). (b) ND-H were found in multi-vesicular body (black arrows) and in late endosome as expected from the endocytosis process. (c) Macropinosomes containing ND-H. (d) Large vesicle containing a dense aggregate of NDs, with some of them located outside the vesicle (black arrows). (b): images from the "cell pellet" preparation (see main text); (a) (c) and (d): images from "cell monolayer" preparation. Scale bars: a): $100 \mathrm{~nm} \mathrm{b)} \mathrm{c)} \mathrm{d):} 500 \mathrm{~nm}$. Magnifications: a) x50,000, (inset: $x 140,000$ ), c) x20,000, b) and d) x30,000. Mb: cellular membrane; Gg: golgi apparatus; Mt: mito- chondria; MVB: multivesicular body, LE: late endosome; MP: macropinosome; Nu: nucleus.

Vesicles containing a large amount of ND-H are also observed (Fig. 4d), with some ND-H located next but outside the vesicle. These ND-H may have escaped from the vesicle, leading to the release of the siRNA in the cytoplasm which is necessary for its gene inhibition activity.

\subsection{Inhibition of EWS/FLI-1 expression in A763 human Ewing sarcoma cells}

To confirm that ND-H are able to deliver an efficient siRNA to cells, we studied the inhibition of targeted EWS/FLI-1 gene by ND-H vectorised siRNA. After the cell incubation with the antisens siRNA targeting EWS/FLI-1 or an irrelevant control siRNA for 24 hours, the level of EWS/FLI-1 mRNA was determined by RT-qPCR. We observed on Fig. 5 that free siRNA 
had no effect on EWS/FLI-1 mRNA expression. When cells were treated by ND-H/siRNA we observed $70 \%$ inhibition of the gene expression. In the same conditions, the control ND$\mathrm{H} /$ siRNA complex has no effect.

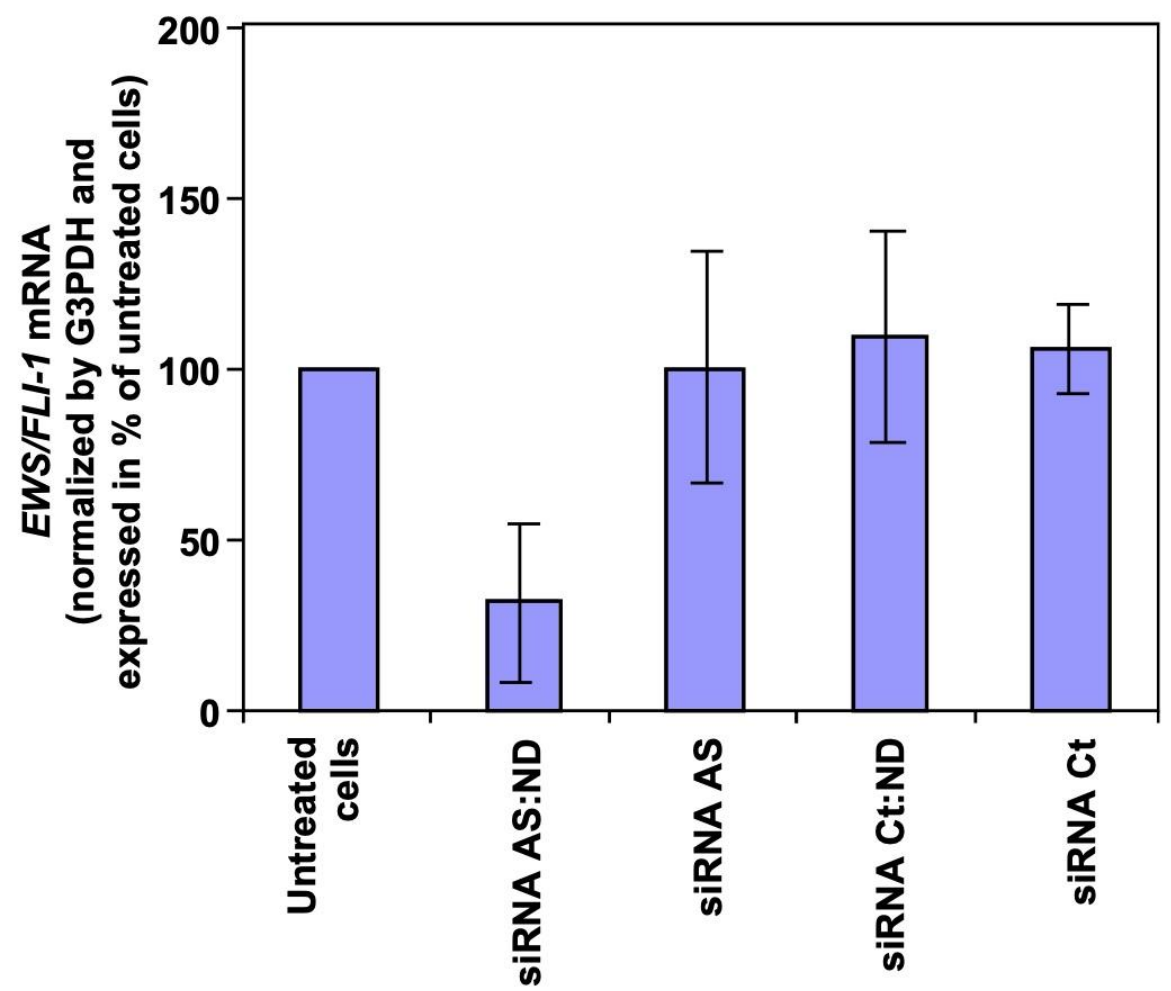

Fig. 5. Inhibition of EWS/FLI-1 mRNA expression measured by RT-qPCR after $24 \mathrm{~h}$ treatment of A673 Ewing Sarcoma cells by ND-H vectorized siRNA, either antisens (siRNA AS:ND) or control (siRNA Ct:ND), at a mass ratio of 50 (siRNA/ND, w/w). Free siRNA, antisens (siRNA AS) or control (siRNA Ct), did not change target gene expression compared to untreated cells.

Therefore the binding of antisens siRNA to ND-H promotes an efficient inhibition of EWS/FLI-1 expression in A673 cells. This effect is specific because irrelevant (control) siRNA vectorised by ND-H have no effect on gene expression. This result indicates that hydrogenation of ND surface is a good strategy to create cationic charge onto the diamond surface and make it a good vector for the delivery of siRNA into cells.

\subsection{Effect of the association between vincristine and EWS/FLI-1 inhibition by ND-H/siRNA in A763 cells}

It was shown that when EWS/FLI-1 expression is abolished in A673 Ewing sarcoma cells after a double transfection, the cell growth is inhibited [19]. Indeed EWS/FLI-1 can deregulate the insulin growth factor IGF-1 proliferation and survival signaling, or inhibit the cell death by blocking pro-apoptotic genes [20], resulting in cell proliferation and cancer formation. We have then hypothesized that inhibition of EWS/FLI-1 by siRNA could restore the cells sensitivity to apoptosis and therefore increase the cytotoxicity of chemiotherapeutic agent, that can then be used at lower dose limiting the side effects. To test this hypothesis, we have used siRNA vectorized by ND-H in association with vincristine, a compound used in the treatment of Ewing sarcoma cancer [21, 22]. 

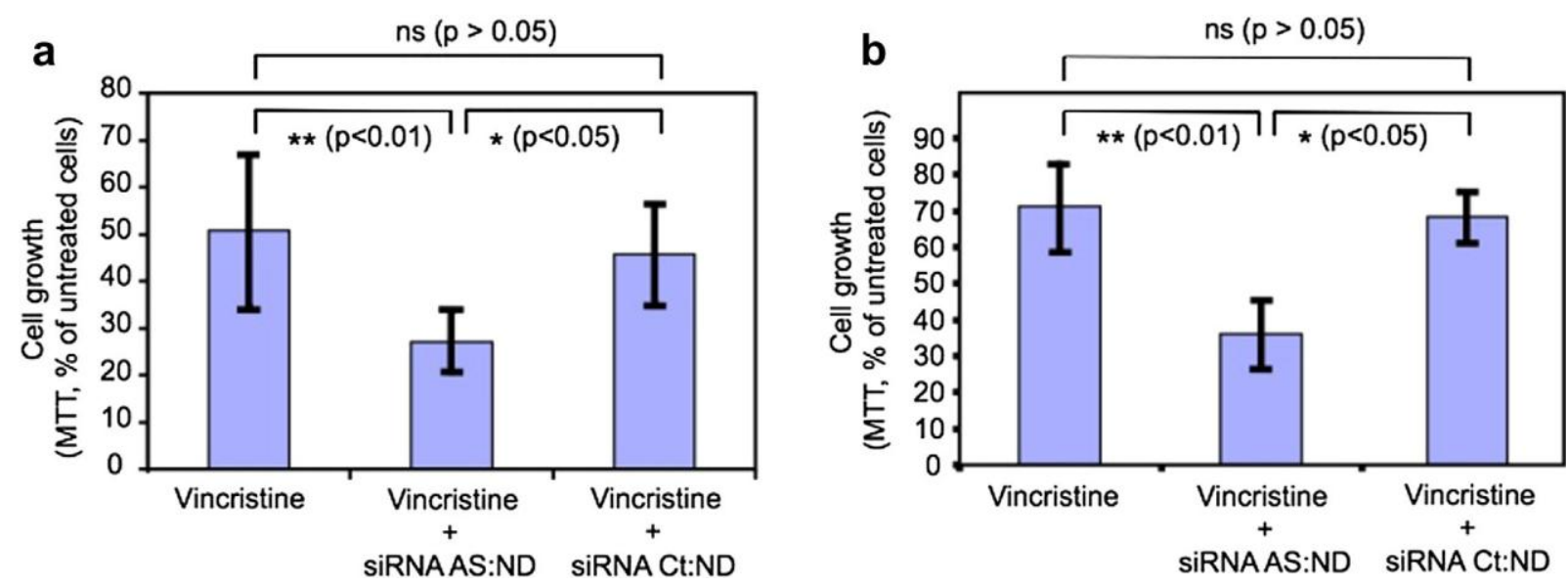

Fig. 6. (a) A673 cells treated by vincristine $0.5 \mathrm{ng} / \mathrm{mL}$ for $24 \mathrm{~h}$ in the presence of $50 \mathrm{nM}$ siRNA antisens (siRNA AS:ND) or control (siRNA Ct:ND) vectorized by ND-H at a mass ratio of 50 (siRNA/ND, w/w). (b) A673 cells treated by vincristine $0.03 \mathrm{ng} / \mathrm{mL}$ for $24 \mathrm{~h}$ in the presence of $50 \mathrm{nM}$ siRNA AS or Ct vectorized by ND-H at mass ratio of 50 (siRNA/ND, w/w).

This association was studied on A673 cell by a MTT essay. Two doses of vincristine were used: $0.5 \mathrm{ng} / \mathrm{mL}$ corresponding to the $\mathrm{IC}_{50}$ efficient concentration (Fig. $6 \mathrm{a}$ ) and a lower dose of $0.03 \mathrm{ng} / \mathrm{mL}$ giving $30 \%$ growth inhibition compared to untreated cells (Fig. $6 \mathrm{~b}$ ). Cells were then treated by both vincristine and $50 \mathrm{nM}$ siRNA vectorized by ND-H. We observed that control siRNA did not modify the efficacy of vincristine. When we add siRNAs targeting EWS/FLI-1 gene vectorized by ND-H, the toxic effect of vincristine is increased to $75 \%$ at the high dose, and to $60 \%$ at low dose. Without vincristine, vectorized siRNA had no effect on the cell growth after $24 \mathrm{~h}$ incubation time (results not shown).

These results indicates that the association of vincristine with ND-H vectorized siRNA targeting EWS/FLI-1, potentiates the cytotoxicity of vincristine, even at a dose more than ten fold lower than the $\mathrm{IC}_{50}$ ones.

\section{Conclusions}

In this study, we showed that nanodiamond with a primary core size of $7 \mathrm{~nm}$ compatible with elimination in urine, that are made cationic by plasma hydrogenation, can efficiently bind siRNA targeted against EWS/FLI-1 Ewing sarcoma junction oncogene and strongly inhibit its expression in cells in culture. In addition, we showed that ND-H/siRNA treatment enhance the cytotoxic effect of vincristine, a chemio-therapeutic agent already used in clinics to treat Ewing sarcoma. Therefore ND-H constitutes a very promising platform for siRNA delivery in anti-cancer therapy.

\section{Acknowledgements}

This work was funded by the Region lle de France through grants from the "domaine d'intérêt majeur" Nano'K (project "UltraDiamEwing", grant $n^{\circ}{ }^{\circ} 13012333$ ) and the "groupe d'intérêt public" Cancéropole lle de France (project "NanoDEwing", grant n²013-2-INV-03CNRS Est-1).

\section{References}


[1] Slegerova J, Rehor I, Havlik J, Raabova H, Muchova E, Cigler P. Intracellular delivery II, vol. 7. Netherlands, Dordrecht: Springer; 2014. p. 363e401.

[2] Perevedentseva E, Lin Y-C, Jani M, Cheng C-L. Biomedical applications of nanodiamonds in imaging and therapy. Nanomedicine 2013;8:2041e60.

[3] Paget V, Sergent JA, Grall R, Altmeyer-Morel S, Girard HA, Petit T, et al. Carboxylated nanodiamonds are neither cytotoxic nor genotoxic on liver, kidney, intestine and lung human cell lines. Nanotoxicology 2014;8:46e56.

[4] Vaijayanthimala V, Cheng P, Yeh S-H, Liu K-K, Hsiao C, Chao J, et al. The long- term stability and biocompatibility of fluorescent nanodiamond as an in vivo contrast agent. Biomaterials 2012;33:7794e802.

[5] Krueger A, Lang D. Functionality is key: recent progress in the surface modification of nanodiamond. Adv Funct Mater 2012;22:890e906.

[6] Smith AH, Robinson EM, Zhang X-Q, Chow EK, Lin Y, Osawa E, et al. Triggered release of therapeutic antibodies from nanodiamond complexes. Nanoscale 2011;3:2844e8.

[7] Zhang X-Q, Chen M, Lam R, Xu X, Osawa E, Ho D. Polymer-functionalized nanodiamond platforms as vehicles for gene delivery. ACS Nano 2009;3: 2609e16.

[8] Chen M, Zhang X-Q, Man HB, Lam R, Chow EK, Ho D. Nanodiamond vectors functionalized with polyethylenimine for siRNA delivery. J Phys Chem Lett 2010;1:3167e71.

[9] Alhaddad A, Adam M-P, Botsoa J, Dantelle G, Perruchas S, Gacoin T, et al. Nanodiamond as a vector for siRNA delivery to Ewing sarcoma cells. Small 2011;7:3087e95.

[10] Alhaddad A, Durieu C, Dantelle G, Le Cam E, Malvy C, Treussart F, et al. In- fluence of the internalization pathway on the efficacy of siRNA delivery by cationic fluorescent nanodiamonds in the Ewing sarcoma cell model. PLoS One 2012;7:e52207.

[11] Soo Choi H, Liu W, Misra P, Tanaka E, Zimmer JP, Itty Ipe B, et al. Renal clearance of quantum dots. Nat Biotechnol 2007;25:1165e70.

[12] Girard HA, Arnault JC, Perruchas S, Saada S, Gacoin T, Boilot J-P, et al. Hydrogenation of nanodiamonds using MPCVD: a new route toward organic functionalization. Diam Relat Mater 2010;19:1117e23.

[13] Mochalin VN, Shenderova O, Ho D, Gogotsi Y. The properties and applications of nanodiamonds. Nat Nanotechnol 2011;7:1e13.

[14] Arnault J-C, Petit T, Girard HA, Chavanne A, Gesset CC, Sennour M, et al. Surface chemical modifications and surface reactivity of nanodiamonds hydrogenated by CVD plasma. Phys Chem Chem Phys 2011;13:11481e7.

[15] Girard HA, Gacoin T, Petit T, Perruchas S, Gesset C, Arnault JC, et al. Surface properties of hydrogenated nanodiamonds: a chemical investigation. Phys Chem Chem Phys 2011;13:11517e23.

[16] Petit T, Girard HA, Trouvé A, Batonneau-Gener I, Bergonzo P, Arnault J-C. Surface transfer doping can mediate both colloidal stability and self-assembly of nanodiamonds. Nanoscale 2013;5:8958e62.

[17] Faklaris O, Garrot D, Joshi V, Druon F, Boudou J, Sauvage T, et al. Detection of single photoluminescent diamond nanoparticles in cells and study of the internalization pathway. Small 2008;4:2236e9.

[18] Chang Y-R, Lee H-Y, Chen K, Chang C-C, Tsai D-S, Fu C-C, et al. Mass production and dynamic imaging of fluorescent nanodiamonds. Nat Nanotechnol 2008;3:284e8. 
[19] Prieur A, Tirode F, Cohen P, Delattre O. EWS/FLI-1 silencing and gene profiling of Ewing cells reveal downstream oncogenic pathways and a crucial role for repression of insulin-like growth factor binding protein 3. Mol Cell Biol 2004;24:7275e83.

[20] Kontny U. Regulation of apoptosis and proliferation in Ewing's sarcoma: opportunities for targeted therapy. Hematol Oncol 2006;24:14e21.

[21] Martins AS, Mackintosh C, Martín DH, Campos M, Hernandez T, Ordoñez J-L, et al. Insulin-like growth factor I receptor pathway inhibition by ADW742, alone or in combination with imatinib, doxorubicin, or vincristine, is a novel therapeutic approach in Ewing tumor. Clin Cancer Res 2006;12: 3532e40.

[22] Raciborska A, Bilska K, Drabko K, Chaber R, Pogorzala M, Polczyn K. Vincristine, irinotecan, and temozolomide in patients with relapsed and refractory Ewing sarcoma. Pediatr Blood Cancer 2013:1621e5. 


\section{Supporting Information}

1. Dynamic Light Scattering measurements

(a)

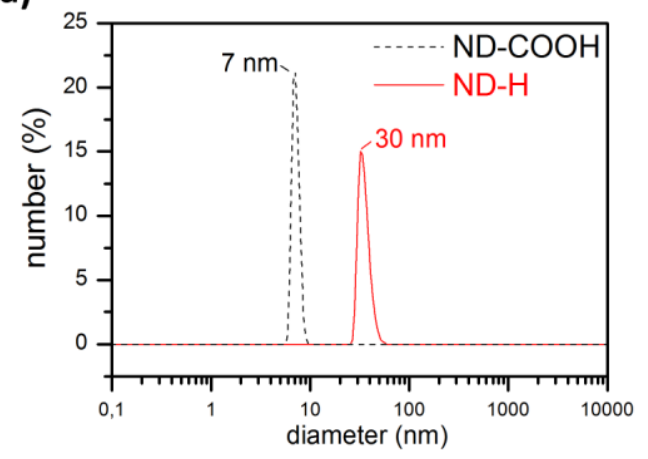

(b)

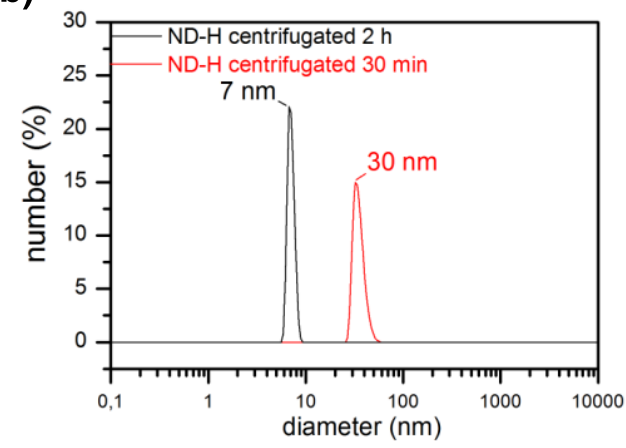

(c)

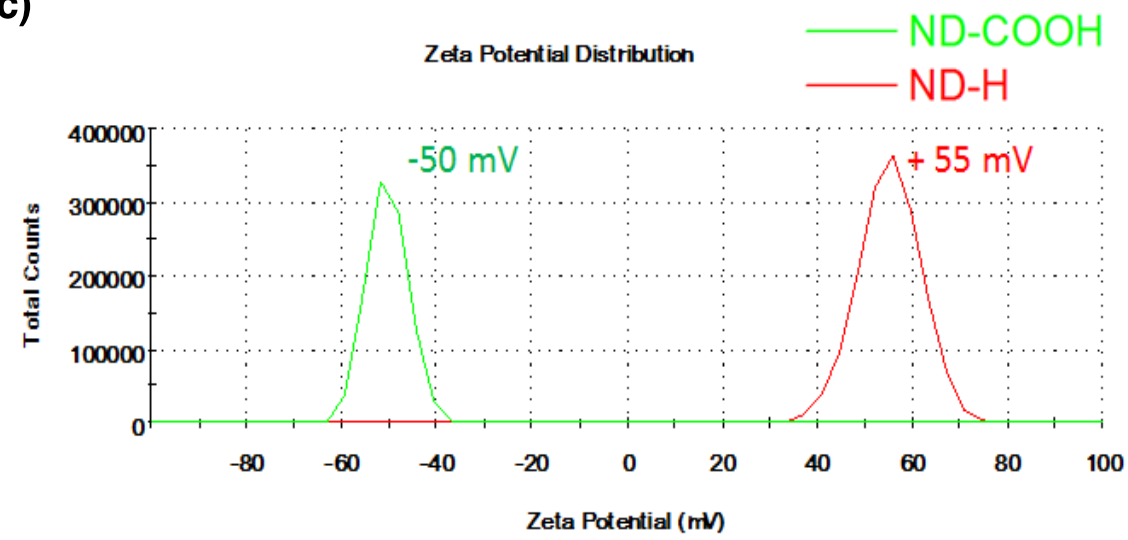

Fig. S1 : (a)-(b) Size distribution and (c) Zeta Potential measurements of ND-H and ND-COOH.

2. Zeta measurements have been performed for ND-H with siRNA in buffer and in buffer + serum.

\begin{tabular}{|l|c|c|c|c|}
\hline & $\begin{array}{l}\text { ND-H } \\
\text { in water }\end{array}$ & $\begin{array}{l}\text { ND-H in } \\
\text { buffer }\end{array}$ & $\begin{array}{l}\text { ND-H + siRNA in } \\
\text { buffer }\end{array}$ & $\begin{array}{l}\text { ND-H + siRNA } \\
\text { in buffer + serum }\end{array}$ \\
\hline Zeta potential $(\mathrm{mV})$ & +54 & +21 & -15 & -10 \\
\hline
\end{tabular}

Table S1 : Zeta potential values

\section{Confocal raster scan of cell after internalization of FITC-labeled-siRNA/ ND-H complex.}

Fig. S2 shows confocal raster scan of a Ewing sarcoma cell fixed after internalization of FITClabeled-siRNA/ND-H complexes. Fig. S2b red channel shows some localized signal that partly superimposed with FITC signal (Fig. S2c) as evidenced by the composite Fig. S2e. The red fluorescence comes from nitrogen vacancy color center NV defects in diamond. Nitrogen impurity and vacancy in substitutional sites of the diamond matrix form these NV defects. Nitrogen is naturally present in nanodiamond at content larger than $100 \mathrm{ppm}$. Vacancies are usually created with high energy particle beam irradiation followed by high temperature $\left(800^{\circ} \mathrm{C}\right)$ annealing, which allows vacancy migration within the diamond lattice. ${ }^{1-3}$ Fig. S2b and Fig. S2f shows the presence of neutrally charged $\mathrm{NV}^{\circ}$ center in the ND internalized by the cells. Since we did not irradiate the $5 \mathrm{~nm}$ detonation nanodiamonds, we hypothesized that the detonation ND contain a non-negligible concentration of native vacancies, and that the plasma treatment leads to an increase in temperature sufficient to form new NV centers. 

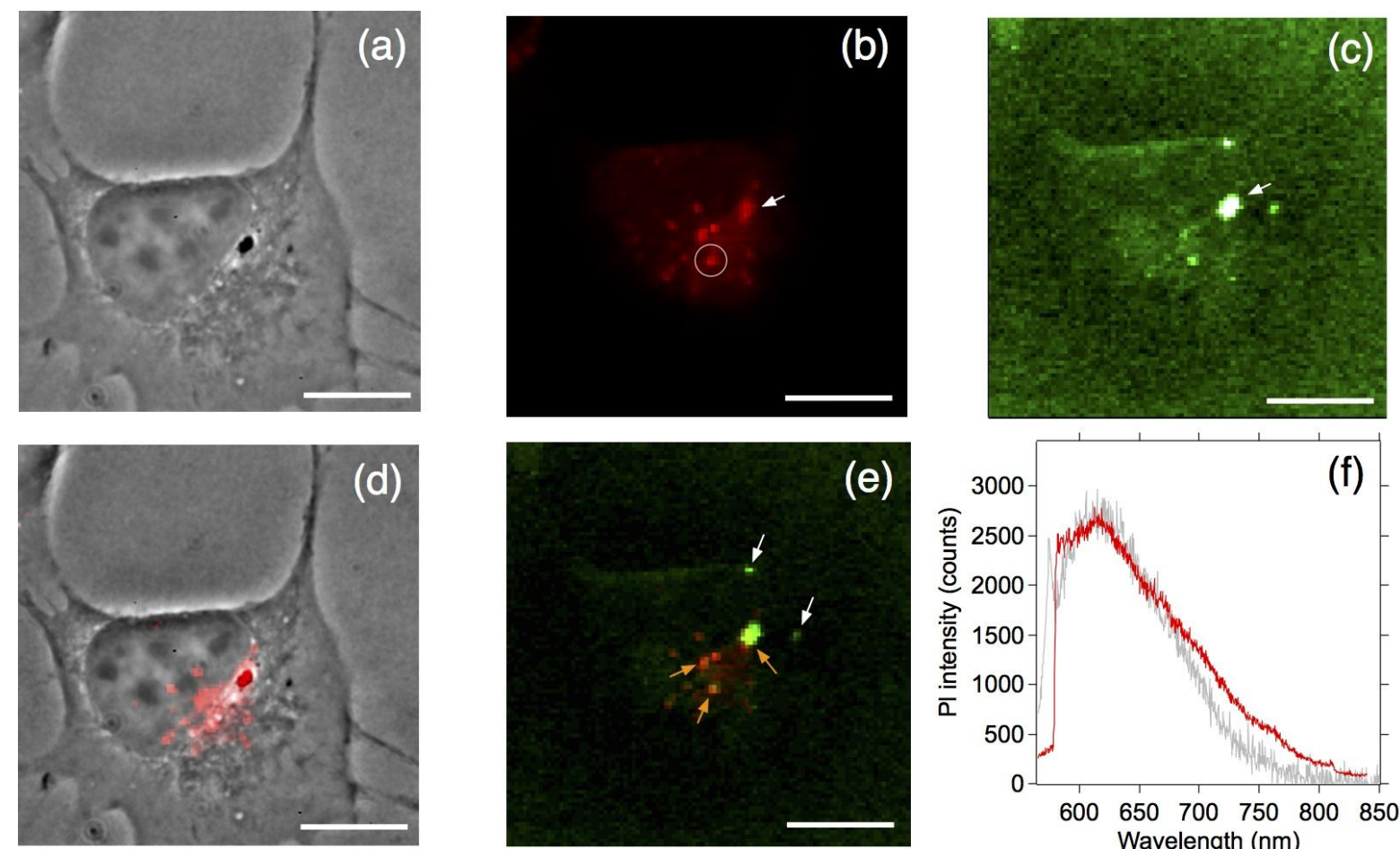

Fig. S2 - Confocal fluorescence raster scan of one Ewing sarcoma cell A673 incubated with FITC labeledsiRNA/ND-H complexes for 3 hours, then fixed. (a) Phase contrast image of the cell (microscope objective: magnification x60, numerical aperture 1.40). (b) Fluorescence scan of the cell with $\mathrm{cw}$ laser excitation at $561 \mathrm{~nm}$ wavelength (power $100 \mu \mathrm{W}$ ) and detected with a high pass filter (cutoff wavelength: $580 \mathrm{~nm}$ ). The red spots are attributed to the fluorescence of ND-H. The spot indicated by the white arrow is the large aggregate appearing as the biggest black spot in (a). (c) Fluorescence scan of the same field of view as in (b) with a laser excitation wavelength $488 \mathrm{~nm}$ (power $1 \mu \mathrm{W}$ ) to observe the localization of FITC-labelled siRNA. Detection of The image is saturated (5000 counts corresponding to white color) on purpose to display the dimmest spots compared to the fluorescence coming from the aggregate (white arrow, the maximum count number is 20234). (d) Overlay of (a) and (b) showing that the nanodiamonds are localized in the perinuclear region. ND superimposed to the nucleus may be located on top of it. No evidence of ND nuclear internalization have been reported so far. (e) Overlay of (b) and (c) fluorescence scans showing (orange arrows) some colocalized spots in agreement with the presence of siRNA around the ND-H. White arrows indicate the presence of siRNA no more grafted to ND (potentially released), or attached to non-fluorescent ND. (f) Photoluminescence spectrum (in red) of the spot surrounded by a white circle in (b). Excitation laser wavelength $561 \mathrm{~nm}$ (power: $100 \mu \mathrm{W}$ ). The spectrum is cut at the lower wavelength due to the longpass filter. The spectrum is typical from neutrally charged nitrogen-vacancy center $\left(N V^{\circ}\right)$, which spectrum is shown on the same plot (grey line) normalized at the same maximum (the $\mathrm{NV}^{\circ}$ spectrum displayed was obtained using a $\mathrm{cw}$ excitation laser at wavelength $532 \mathrm{~nm}$ ). All scale bars in (a)-(e): $10 \mu \mathrm{m}$

\section{References}

1. Y.-R. Chang, H.-Y. Lee, K. Chen, C.-C. Chang, D.-S. Tsai, C.-C. Fu, T.-S. Lim, Y.-K. Tzeng, C.Y. Fang, C.-C. Han, H.-C. Chang, and W. Fann, Nat. Nanotechnol., 2008, 3, 284-8.

2. J.-P. Boudou, P. A. Curmi, F. Jelezko, J. Wrachtrup, P. Aubert, M. Sennour, G. Balasubramanian, R. Reuter, A. Thorel, and E. Gaffet, Nanotechnology, 2009, 20, 235602.

3. G. Dantelle, a. Slablab, L. Rondin, F. Lainé, F. Carrel, P. Bergonzo, S. Perruchas, T. Gacoin, F. Treussart, and J.-F. J.-F. Roch, J. Lumin., 2010, 130, 1655-1658. 